\title{
Elevated heme impairs macrophage phagocytosis in endometriosis
}

\author{
Yu-Yin Liu ${ }^{1, *}$, Yu-Kai Liu ${ }^{1}, *$, Wen-Ting Hu ${ }^{1}$, Ling-Li Tang${ }^{1}$, Yan-Ran Sheng ${ }^{1}$, Chun-Yan Wei ${ }^{1}$, \\ Ming-Qing $\mathrm{Li}^{1,2,3}$ and Xiao-Yong Zhu ${ }^{1,2,3}$ \\ ${ }^{1}$ Laboratory for Reproductive Immunology, Hospital of Obstetrics and Gynecology, Fudan University, Shanghai, \\ People's Republic of China, ${ }^{2}$ NHC Key Lab of Reproduction Regulation (Shanghai Institute of Planned Parenthood \\ Research), Hospital of Obstetrics and Gynecology, Fudan University, Shanghai, People's Republic of China and \\ ${ }^{3}$ Shanghai Key Laboratory of Female Reproductive Endocrine Related Diseases, Shanghai, People's Republic \\ of China
}

Correspondence should be addressed to M-Q Li or X-Y Zhu; Email: mqli@fudan.edu.cn or zhuxiaoyong@fudan.edu.cn

*(Y-Y Liu and Y-K Liu contributed equally to this work)

\begin{abstract}
Endometriosis (EMS) is a chronic inflammatory disease characterized by the presence of extrauterine endometrial tissues. It has been previously reported that the refluxed blood containing viable endometrial tissues and the defective elimination of peritoneal macrophages in the pelvic cavity may involve in EMS pathogenesis. However, the mechanism by which macrophages exhibit attenuated phagocytic capability in EMS remains undetermined. Herein, we found that heme, the byproduct of lysed erythrocytes, accumulated abnormally in the peritoneal fluid (PF) of patients with EMS (14.22 $\mu \mathrm{mol} / \mathrm{L}, 95 \%$ confidence interval (CI): 12.54-16.71), compared with the EMS-free group $(9.517 \mu \mathrm{mol} / \mathrm{L}, 95 \% \mathrm{Cl}: 8.891-10.1053)$. This abnormal accumulation was not associated with the color of $\mathrm{PF}$, phase of the menstrual cycle or severity of the disease. The reduced phagocytic ability of peritoneal macrophages (pM $\varphi s$ ) was observed in the EMS group. Consistently, a high-concentration $(30 \mu \mathrm{mol} / \mathrm{L})$ heme treatment impaired EMS-pM $\varphi s$ phagocytosis more than a low-concentration $(10 \mu \mathrm{mol} / \mathrm{L})$ heme treatment. A similar phenomenon was observed in the EMS-free control pMps (Ctrl-pM $\varphi s)$ and the $\mathrm{CD}_{14}{ }^{+}$peripheral monocytes $\left(\mathrm{CD} 14^{+}\right.$Mos). These results indicated that a high heme concentration exhibits a negative effect on macrophage phagocytosis, which supplements the mechanism of impaired scavenger function of pMes in EMS. Reproduction (2019) 158 257-266
\end{abstract}

\section{Introduction}

Endometriosis (EMS) is a chronic inflammatory disease that is characterized by the presence of extrauterine endometrial-like tissue. EMS is estimated to affect approximately $5-10 \%$ women of reproductive age who exhibit pelvic pain, dysmenorrhea, dyspareunia and infertility (Zondervan et al. 2018). To some extent, these symptoms can be alleviated via treatment including with hormonal medication or surgical lesion removal. However, patients have been revealed to exhibit undesirable side effects like contraception with progestin drug treatment and have a post-operative EMS recurrence of $30-50 \%$ after $2-5$ years (Vercellini et al. 2010, Leeners et al. 2018). Hence, this disease not only causes enormous physical and psychological distress on patients (Gambadauro et al. 2019), but also imposes a heavy economic burden on their families as well as the national health care system (Soliman et al. 2018).

The most widely accepted hypothesis for the etiology of EMS is Sampson's theory of retrograde menstruation
(Sampson 1927). Menstrual blood from the uterine cavity is refluxed through the fallopian tubes and releases erythrocytes, endometrial tissue and cell debris into the peritoneal environment, and subsequently viable endometrial stromal cells (ESCs) implant and grow. Sampson's theory helps to explain the increased prevalence of EMS in women with congenital menstrual outflow tract obstruction (Dietrich et al. 2014) and asymmetrical distribution of endometriotic lesions in the abdominopelvic cavity (Vercellini et al. 2007). However, this theory fails to explain why retrograde menstruation occurs in 61-90\% women (Halme et al. 1984, Symons et al. 2018) but only $10 \%$ develop EMS.

It has also been suggested that the impaired immune surveillance may result from the dysfunction of immune cells, including Foxp3 ${ }^{+}$regulatory $\mathrm{T}$ (Treg) cells, natural-killer (NK) cells and macrophages, and this may contribute to the formation and development of endometrial lesions (Wei et al. 2016, Yang et al. 2017, Symons et al. 2018). Macrophages, as the predominant immune cells in peritoneal cavity, serve a role in 
exacerbating inflammation and sustaining EMS, and the mechanism by which this occurs has gained increased attention in recent years. An accumulation of studies have revealed that macrophage populations are significantly increased in the PF and eutopic endometrium, and proinflammatory cytokines secretion increases (Berbic et al. 2009, Zhang et al. 2018). However, macrophages have also presented decreased phagocytic ability and failure to remove endometriotic tissue from the peritoneal cavity (Riccio et al. 2018), facilitating tissue adhesion to extrauterine structures (Shao et al. 2016, Chan et al. 2017). In previous studies, Mei et al. have linked the impaired phagocytosis with the activation of IL-33 and overexpression of indoleamine 2,3-dioxygenase-1 (IDO1) in ectopic ESCs. Chuang and Wu focused on the suppressive effect of prostaglandin $E_{2}$, which was revealed to reduce scavenger receptor CD36 and matrix metalloproteinases expression (Wu et al. 2005, 2013, Chuang et al. 2009, 2010).

Heme is a complex of iron with protoporphyrin IX (PPIX) and is the prosthetic group of many essential biological proteins. Specially, it participates in the formation of hemoglobin $(\mathrm{Hb})$ and erythrocytes (Immenschuh et al. 2017). During hemolysis, ruptured erythrocytes release $\mathrm{Hb}$. After exhausting the corresponding scavenging proteins haptoglobin ( $\mathrm{Hp}$ ), cell-free $\mathrm{Hb}$ is rapidly oxidized and further releases free heme. Without being chelated, heme can cause oxidative damage and inflammation (Chiabrando et al. 2018). To prevent this harmful effect, heme scavenger hemopexin $(\mathrm{Hx})$ binds to heme and forms a heme- $\mathrm{Hx}$ complex, which is subsequently taken up by cells through receptor-mediated endocytosis. Once incorporated into the cell, heme is degraded by heme oxygenase- $1(\mathrm{HO})$ into equimolar amounts of $\mathrm{CO}$, iron and biliverdin (Vijayan et al. 2018). However, under pathological conditions, the capacity for the organism to scavenge heme may saturate and the increased heme can cause tissue damage via pro-oxidant and immunoregulatory effects (Martins \& Knapp 2018).

Previous studies have demonstrated that women with EMS exhibit shorter menstrual cycles and higher volumes of refluxed menstrual blood compared with healthy women (Parazzini et al. 2017, Shafrir et al. 2018). In patients developing EMS, bleeding from red endometrial lesions may further increase the number of erythrocytes. Therefore, it is reasonable to assume that heme, as a byproduct of lysed erythrocytes, may accumulate in the peritoneal cavity of patients with EMS. This causes a high level of free heme that can exert its oxidative effect and immunoregulatory effect, which may help to build the defective peritoneal disposal system in EMS. Herein we aimed to verify the existence of abnormal heme accumulation in the pelvic cavity of patients with EMS and further assess the association between heme and macrophages. This study revealed the potential effect of heme on $\mathrm{pM} \varphi \mathrm{s}$ phagocytosis.

\section{Materials and methods}

\section{Patients and samples collection}

The current study was approved by The Human Ethics Committee of Obstetrics and Gynecology Hospital, Fudan University. All donors provided written informed consents. The patients included in the current study were premenopausal women (aged 22-49 years) who attended the Obstetrics and Gynecology Hospital of Fudan University between January 2018 and April 2019. No patients received hormonal therapy within 6 months prior to surgery. Endometriosis stage was diagnosed according to the revised American Society for Reproductive Medicine Staging (1997). Endometriotic tissues and endometriotic PF were collected from women who had undergone laparoscopic surgery for ovarian endometriosis $(n=45)$, which was confirmed by pathological assessment. Control endometrial tissues were obtained from premenopausal women who had undergone fractional curettage but exhibited no abnormalities after pathological examination $(n=35)$. Control PF was collected from premenopausal women undergoing laparoscopic surgery but exhibited no evidence of endometriosis, including patients exhibiting uterine fibroid, mature teratoma or ovarian simple cyst $(n=45)$. PF samples were divided into two groups by color and included a reddish and yellowish group. Peripheral blood samples were obtained from healthy volunteers $(n=20)$. All samples were collected under sterile conditions.

\section{ESCs isolation and culture}

Human endometrial and endometriotic tissues were purified as previously described (Wei et al. 2016). Tissues were cut into $1 \mathrm{~mm}$ pieces and digested into single-cell suspensions using collagenase type IV $(0.001 \mathrm{~g} / \mathrm{mL}$, Sigma-Aldrich) for $30 \mathrm{~min}$ at $37^{\circ} \mathrm{C}$ with a constant agitation. Nylon strainers $(100,300$ and $400 \mu \mathrm{m}$ ) were subsequently used to filter the resulting suspension. The filtrate was collected and centrifuged at $288 \mathrm{~g}$ for $8 \mathrm{~min}$ at $4^{\circ} \mathrm{C}$. Later the supernatant was discarded and the cell sedimentation was resuspended in Dulbecco's Modified Eagle Medium (DMEM)/F12 complete medium with 10\% fetal bovine serum (FBS; Hyclone) and $100 \mathrm{U} / \mathrm{mL}$ of penicillin and $100 \mathrm{mg} / \mathrm{mL}$ of streptomycin. Finally, the suspended cells were plated into culture flask in $5 \% \mathrm{CO}_{2}$ at $37^{\circ} \mathrm{C}$. The culture medium was replaced every 3 days. Flow cytometry (FCM) analysis was used to verify the purity of vimentin ${ }^{+}$cytokeratin $7^{-}$ESCs (>95\%). Additionally, the HESC cell line (human ESCs derived from a uterine myoma) was used in the experiments, which was a generous gift from Professor Zhao Dong (Shanghai First Maternity and Infant Hospital, Tongji University). This cell line was maintained in the same condition as the ESC isolated from tissues.

\section{Treatment of PF and peripheral blood}

$\mathrm{PF}$ was centrifuged at $450 \mathrm{~g}$ for $8 \mathrm{~min}$ at $4^{\circ} \mathrm{C}$. The supernatant was collected and stored at $-80^{\circ} \mathrm{C}$. The cell pellet was treated with Red Blood Cell Lysis Buffer (BioLegend, San Diego, USA) for $10 \mathrm{~min}$ at $4^{\circ} \mathrm{C}$ and washed with PBS twice. Subsequently human anti-CD14 microbeads (Miltenyi Biotec, 
Bergisch Gladbach, Germany) were used to select peritoneal macrophages (pM $\varphi s$ ), according to the manufacturer's protocol. Peripheral blood mononuclear cells (PBMCs) were firstly isolated from peripheral blood samples using FicollHypaque density gradient centrifugation. CD14+ monocytes $\left(\mathrm{CD} 14^{+}\right.$Mos) were subsequently purified from PBMCs using human anti-CD14 microbeads. The purity of $\mathrm{pM} \varphi \mathrm{s}$ or $\mathrm{CD} 14^{+}$ Mos was $>95 \%$ as determined by FCM.

\section{Heme measurement}

Peritoneal heme concentration was measured by using the Heme Assay kit (MAK316, Sigma-Aldrich). A total of $250 \mu \mathrm{L}$ of water was added into wells in a 96-well plate to create a blank well, while $50 \mu \mathrm{L}$ of heme calibrator and $200 \mu \mathrm{L}$ of water was mixed to create a standard well. A total of $50 \mu \mathrm{L}$ of samples were pipetted from each PF supernatant and subsequently mixed with $200 \mu \mathrm{L}$ of reagent respectively. After 5 -min incubation at room temperature, the absorbance of well contents was determined at $400 \mathrm{~nm}$. All samples and standards were performed in duplicate. Total heme concentration of a sample was determined using the following equation: $=\left(\mathrm{OD}_{\text {sample }}-\mathrm{OD}_{\text {blank }}\right) /$ $\left(\mathrm{OD}_{\text {calibrator }}-\mathrm{OD}_{\text {blank }}\right) \times 62.5(\mu \mathrm{mol} / \mathrm{L})$.

\section{Heme}

Heme (hemin, Sigma-Aldrich) was first dissolved in dimethyl sulfoxide (DMSO, Sigma-Aldrich) to create a stock concentration of $20 \mathrm{mM}$, filtered through a $0.02 \mathrm{~mm}$ syringe filter unit to assure sterility and subsequently stored at $-20^{\circ} \mathrm{C}$. This was then diluted to different concentrations $(10,30 \mu \mathrm{mol} / \mathrm{L})$ in complete RPMI 1640 medium with 10\% FBS immediately prior to use. Heme concentrations of the ultimate solution were verified by a Heme Assay kit based on the potential FBS interference (which may contains heme per se or heme scavenging proteins, including hemopexin and albumin). The DMSO concentration of the ultimate solution was kept lower than $0.1 \%$ in all experiments.

\section{Quantitative real-time PCR}

Total RNA was extracted from cells using RNAiso Plus reagent (TaKaRa Biotechnology), according to the manufacturer's protocol. Total RNA (500 ng) was reverse transcribed into firststand cDNA (RR036A, TaKaRa Biotechnology) following the manufacturer protocol. cDNA was subsequently amplified with TB Green (RR820A, TaKaRa Biotechnology) and specific primers (detailed sequences listed in Table 1) (Sangon Biotech, Shanghai, China) using the ABI PRISM 7900 Sequence Detection System (Applied Biosystems). PCR was performed for 40 cycles using the following conditions: denaturizing at $95^{\circ} \mathrm{C}$ for $30 \mathrm{~s}$, annealing at $95^{\circ} \mathrm{C}$ for $5 \mathrm{~s}$ and elongation at $60^{\circ} \mathrm{C}$ for $34 \mathrm{~s}$. The mRNA expression of the samples was normalized using the $2^{-\Delta \Delta C T}$ method. All measurements were performed in triplicate.

\section{Phagocytosis assay}

To assess phagocytosis efficiency, $10^{5}$ macrophages were plated into 96-well low attachment plates and treated with different concentration of heme $(10,30 \mu \mathrm{mol} / \mathrm{L})$ or DMSO for $20 \mathrm{~h}$. CFSElabeled (BioLegend) HESCs were then incubated with M $\varphi s$ at a ratio of $1: 1$ at $37^{\circ} \mathrm{C}$ for $4 \mathrm{~h}$. After a 4 -h coculture, cells in the 96 -well plates were transferred to $1.5 \mathrm{~mL}$ EP tubes, washed by PBS and stained with allophycocyanin(APC)-conjugated anti-CD45 (BioLegend) to mark M $\varphi$ s. The phagocytosis ratio was determined using FCM and was calculated as follows: CD $45^{+} \mathrm{CFSE}^{+}$cells $/ \mathrm{CD} 45^{+}$cells $\times 100 \%$.

\section{Flow cytometry (FCM)}

Fluorochrome-conjugated antibodies of human antigens were used for flow cytometry analysis and included allophycocyanin(APC)-conjugated anti-CD45 (BioLegend), Percp/cy5.5-conjugated anti-CD45 (BioLegend), APC/Cy7conjugated anti-CD14 (BioLegend). Cells were washed with PBS on ice and then incubated with the corresponding fluorescent-labeled antibody for $30 \mathrm{~min}$ at $4^{\circ} \mathrm{C}$, according to the recommended dosage. Isotype controls were used. Following incubation, cells were washed in PBS and analyzed immediately. Sample data were collected in a CyAn ADP analyzer (Beckman Coulter) and analyzed using Flowjo version10 software for Windows (Tree Star).

\section{Statistical analyses}

Data collected from at least three independent experiments were analyzed using the Graphpad Prism statistical package (Graphpad Software). Data normality was tested using the Shapiro-Wilk test. Comparisons were performed using an

Table 1 The sequences of primers used for qRT-PCR.

\begin{tabular}{|c|c|c|c|}
\hline Gene & Size (bp) & Forward primer $\left(5^{\prime}-3^{\prime}\right)$ & Reverse primer $\left(5^{\prime}-3^{\prime}\right)$ \\
\hline$A C T B$ & 281 & СТАССТСАТGАAGАТССТСАСС & AGTTGAAGGTAGTTTCGTGGAT \\
\hline CD163 & 127 & GCCACAACAGGTCGCTCATCC & CAAGCCGСTGTCTCTGTCTTCG \\
\hline CD91 & 154 & TTGCTGСTGСTGСTGGTTCTG & GСТСТССGССТTCGTACATСTTG \\
\hline HCP1 & 106 & GCСTTGСTGATAGССАTGAСТСТС & CAATGGATCGGTGGTGACGGAAC \\
\hline FLVCR 1 & 116 & GCTTCGTGGTGCTCCTGATCTTC & GTGCAGCAAGGTGACACCGTAG \\
\hline FLVCR2 & 84 & TGTGCTGCTTGTCATCACCTATGG & TGCCAGATCACCATGCGATTCAG \\
\hline$A B C G 2$ & 123 & GCCATAGCAGCAGGTCAGAGTG & ACTGAAGCCATGACAGCCAAGATG \\
\hline HRG1 & 195 & TTCСTCGTCTGGACGGTGGTC & GCAGAAGGCAGCGATGGAGAC \\
\hline $\mathrm{HO}-1$ & 116 & TGCCAGTGCCACCAAGTTCAAG & TGTTGAGCAGGAACGCAGTCTTG \\
\hline$B A R C H 1$ & 154 & GTGGAGCGAGAAGTGGCAGAAC & TACCTAACCACGGACACTCAGACC \\
\hline NRF2 & 124 & ACGGTATGCAACAGGACATTGAGC & TTGGCTTCTGGACTTGGAACCATG \\
\hline
\end{tabular}


unpaired $t$-test or Mann-Whitney, one-way ANOVA with Turkey's multiple comparisons or Kruskal-Wallis test followed by Dunn's test as indicated in the corresponding figure legends. Data that were normally distributed are presented as the mean \pm S.E.M., while non-normal data are presented as the median $\pm 95 \%$ confidence interval $(\mathrm{Cl})$. Statistical significance is indicated by $P<0.05$.

\section{Results}

\section{The concentration of heme is higher in PF in EMS patients}

The concentration of heme was $14.22 \mu \mathrm{mol} / \mathrm{L}(95 \% \mathrm{Cl}$ : 12.54-16.71) in the supernatant of the PF of patients with endometriosis. This was higher than $9.517 \mu \mathrm{mol} / \mathrm{L}$ (95\% Cl: 8.891-10.1053) in the control group (Fig. 1A). The PF samples were divided into a reddish group and a yellowish group. After centrifugation, all the supernatant became yellow transparent liquid but reddish PF contained more erythrocytes in the pellets. Considering that the number of erythrocytes in PF may interfere with the concentration of heme, the heme level in the reddish PF and yellowish PF was assessed and no significant differences were exhibited (Fig. 1B). The heme level of the EMS and control group was also examined in relation to the PF color. This revealed that heme level in the EMS group was always higher than that in control group, irrespective of PF color (Fig. 1C). Samples were subsequently classified by menstrual cycle and disease severity but no differences were exhibited between groups (Fig. 1D and E).

\section{Heme metabolism molecules are elevated in both ectopic ESCs and the pM}

To explore if heme exhibited an effect on ESCs, qRT-PCR was used to evaluate the expression of the molecules associated with heme metabolism. CD163 and CD91 are the receptors that mediate the $\mathrm{Hb}-\mathrm{Hp}$ complex internalization and heme-Hx complex internalization respectively. This results in cellular heme uptake (Ponka et al. 2017). The cytoplasmic heme importer, named heme carrier protein1 (HCP1), is expressed in the cytoplasmic membrane of duodenal epithelial cells and is believed to participate in dietary heme absorption. Feline leukemia virus subgroup $C$ receptor (FLVCR) 2 is an additional protein that has been revealed to mediate heme uptake (Fujiwara \& Harigae 2015). HRG1 has been demonstrated to be a special heme transporter due to the fact that it localizes to the phagolysosomal membranes and transports heme from the phagolysosome to the cytoplasm during erythrophagocytosis (White et al. 2013). Once delivered inside cells, heme is used to generate new hemoproteins or is catabolized by $\mathrm{HO}-1$. The activation of $\mathrm{HO}$ is regulated via a heme-dependent pathway that is associated with the downregulation of the nuclear transcriptional repressor BTB domain and CNC homolog 1 (BACH1) and the upregulation of
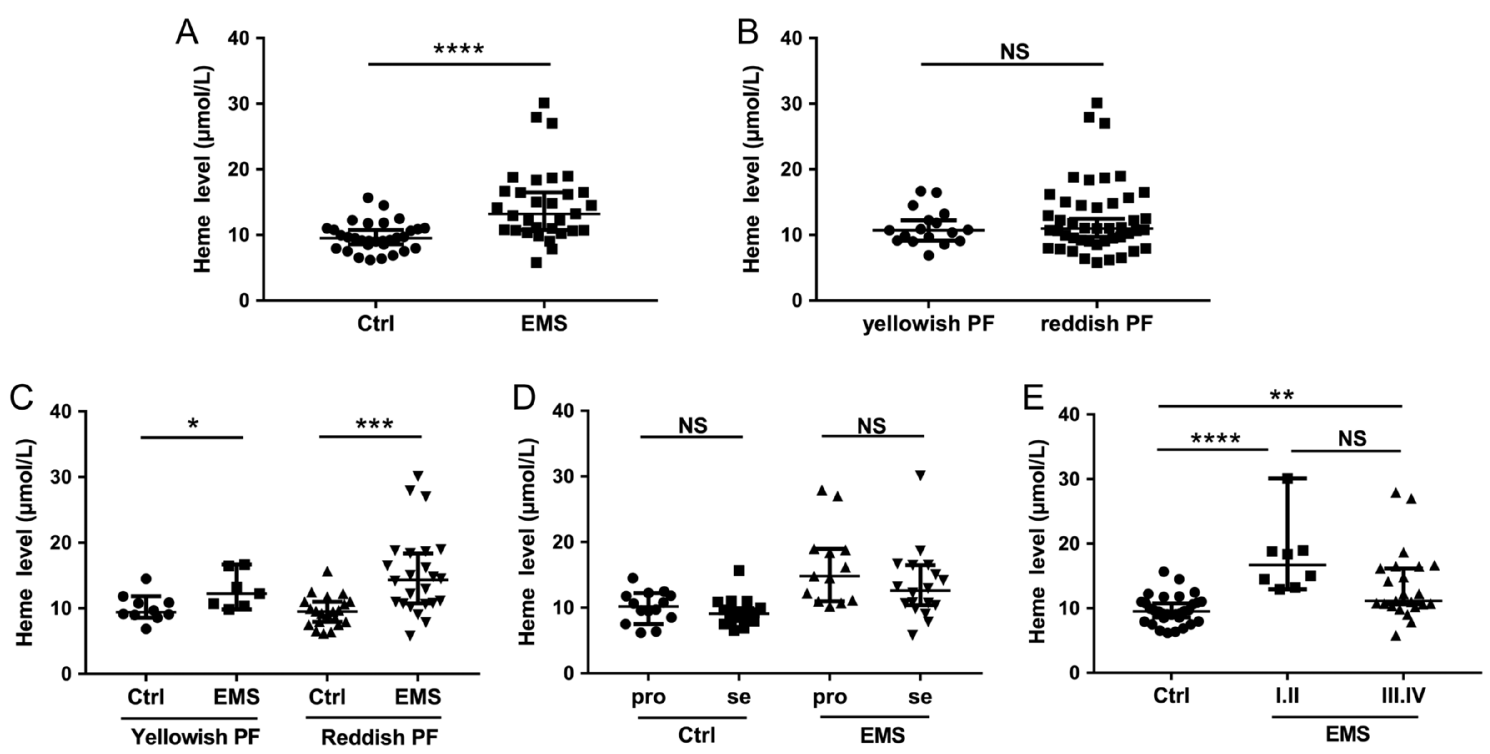

Figure 1 The concentration of heme is higher in the peritoneal fluid of endometriosis patients. (A) Peritoneal heme level in control group ( $n=31$ ) and endometriosis group $(n=31)$. (B) Heme level in yellowish peritoneal fluid $(n=17)$ and reddish peritoneal fluid $(n=45)$. (C) Heme level in yellowish peritoneal fluid of the control group $(n=10)$ and endometriosis group $(n=7)$, in reddish peritoneal fluid of the control group $(n=21)$ and endometriosis group $(n=24)$. (D) Peritoneal heme level of the control group in the proliferative phrase $(n=14)$ and in the secretary phrase $(n=17)$, of endometriosis group in the proliferative phrase $(n=13)$ and in the secretary phrase $(n=18)$. (E) Peritoneal heme level in the control $(n=31)$ and the endometriosis group of I/II stages $(n=8)$ and III/IV stages $(n=23)$. In $(\mathrm{A}, \mathrm{B}, \mathrm{C}, \mathrm{D}$ and $\mathrm{E})$, data are presented as the median with $95 \% \mathrm{Cl}$. Mann-Whitney test (A, B, C and D), Kruskal-Wallis test with Dunn's multiple comparison test (E); ${ }^{*} P<0.05,{ }^{* *} P<0.01, * * * P<0.001$, $* * * * P<0.0001, \mathrm{NS}$, no significance. 
nuclear transcription erythroid 2-related factor (NRF2) (Chiang et al. 2018). Excess heme, produced subsequent to the degradation system being overwhelmed, is transported out of the cell via cell-surface heme exporter FLVCR1 and PPIX exporter ATP-binding cassette protein (ABCG2) (Immenschuh et al. 2017) (Model graph seen in Fig. 2A).

We found that compared with normal ESCs (NESCs), ectopic ESCs (EESCs) upregulated the expression of CD91, FLVCR2, HO-1 and NRF2 and downregulated $\mathrm{BACH} 1$, suggesting that an increased amount of heme was transported into cells and catabolized. Heme exporter ABCG2 was also upregulated (Fig. 2B). The expression of these molecules in the peritoneal macrophages of endometriotic patients (EMS-pM $\varphi s$ ) was also compared with patients who did not exhibit EMS (Ctrl-pM $\varphi s)$. Similar trends were demonstrated in the peritoneal macrophage. However, only HO-1 and HRG 1 expression exhibited significant differences when compared with the control and the EMS group had significant differences (Fig. 2C).

\section{Impaired phagocytosis of pM $\varphi$ s in patients with EMS}

To further assess the phagocytosis of macrophage from EMS patients, firstly the purity of macrophages isolated from PF was investigated and the result revealed that macrophage purity was above 95\% (Fig. 3A). FCM data revealed that the phagocytosis ratio of peritoneal macrophages in EMS was lower compared with the control group (Fig. 3B and C), which was consistent with results of previously published studies (Wu et al. 2013).

\section{High level of heme impairs the phagocytic ability of macrophage}

To investigate whether the effect of heme on macrophage phagocytosis was universal or not, three types of macrophages, including peritoneal macrophage from patients with EMS (EMS-pM $\varphi$ ) or without EMS (Ctrl-pM $\varphi$ ) and $\mathrm{CD} 14^{+}$peripheral monocyte $\left(\mathrm{CD} 14^{+} \mathrm{Mo}\right)$ were used. Subsequent to the isolation from the PF or PBMC by anti-CD14 microbeads, three kinds of macrophages were treated with different concentration of heme or DMSO in 96 wells for $20 \mathrm{~h}$ respectively, prior to coculture. Medium with a $10 \mu \mathrm{mol} / \mathrm{L}$ heme concentration was used to mimic the low heme peritoneal environment of the control group, while medium with $30 \mu \mathrm{mol} / \mathrm{L}$ heme was used to mimic the high heme peritoneal environment in the EMS group.

The results revealed that a higher heme concentration impaired the phagocytic ability of EMS-pM $\varphi$ when compared with the low heme concentration treatment (Fig. 4A and B). A similar phenomenon has been observed in Ctrl-pM $\varphi$ and CD14 $4^{+} \mathrm{Mo}$ (Fig. 4C, D and E). However, when compared with the DMSO treatment, the effect of a low heme concentration was varied in different macrophages. In the $\mathrm{CD}_{14}{ }^{+}$Mo group, the negative effect of heme on the phagocytic ratio was dose dependent (Fig. 4F). In relation to EMS-pM $\varphi$ or $\mathrm{Ctrl}-\mathrm{pM} \varphi$, the dose-dependent phenomenon was not observed (Fig. 4B and D).

\section{Discussion}

This study has found that women with EMS had significantly higher heme levels in the PF compared with the control group. Heme level was not correlated with the differences in PF color, phase of menstrual cycle or disease severity. However, it should be noted that previous work performed by Wolfler revealed no significant differences in peritoneal heme concentration between an endometriosis group or control group (Wolfler et al. 2013). Possible explanations for the discrepancies between the studies may be due to different methods of centrifugation (not mentioned in Wolfler's article) and PF sample size. Wolfler verified lower $\mathrm{Hx}$ level in the PF of patients with EMS. Hx exhaustion, being the scavenger protein with highest binding affinity to heme, usually indicates the presence of increased heme (Hahl et al. 2017).

There is an abundance of indirect evidence in previous research implying a heme overload in the peritoneal environment of patients with EMS. The increased $\mathrm{Hb}$ concentration has been revealed in the PF (Van Langendonckt et al. 2002), providing possibilities for the accumulation of its byproduct, heme. It is well known that $\mathrm{HO}-1$, the inducible $\mathrm{HO}$ isoform, is highly upregulated by heme to protect cells against oxidative damage and apoptosis (Immenschuh et al. 2017). In the results gained in the present study, $\mathrm{HO}-1$ overexpression was revealed in EESC and EMS-pM $\varphi$, indicating that cells may live in a high heme environment. Additionally, cells exhibiting FLVCR2 overexpression were demonstrated to exhibit a heightened sensitivity to heme overload (Duffy et al. 2010). The results of the current study identified the upregulation of FLVCR2 and an additional heme importer CD91, in EESC. Notably, EESC also increased the expression of heme exporter $A B C G 2$, which may indicate that the intracellular heme degradation system is overwhelmed and excess heme requires exportation out of cell to avoid heme toxicity. The differential gene expressions of heme metabolism molecules further sustains the assumption that heme is accumulated in the peritoneal cavity of EMS patients.

Many studies have concluded that heme serves a role as an oxidant in the pathogenesis of EMS (Van Langendonckt et al. 2002, Iwabuchi et al. 2015, Vitale et al. 2018). Heme can trigger reactive oxygen species (ROS) production, exacerbating the oxidant/antioxidant imbalance in EMS (Donnez et al. 2016). Excess ROS can cause oxidative damage in the peritoneal mesothelium, inducing adhesion for ESC. On the other hand, the metabolism of heme by $\mathrm{HO}-1$ can generate 
A

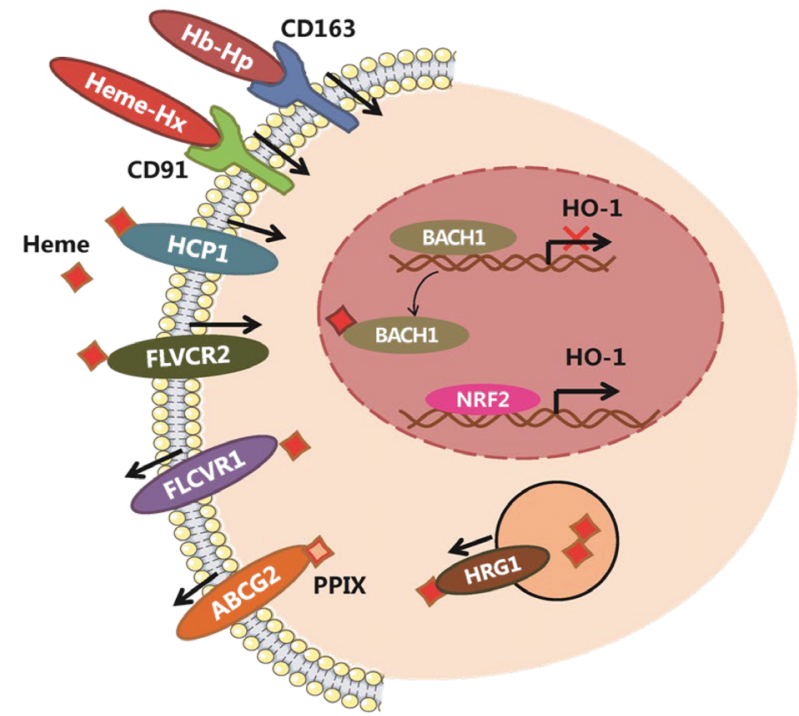

B
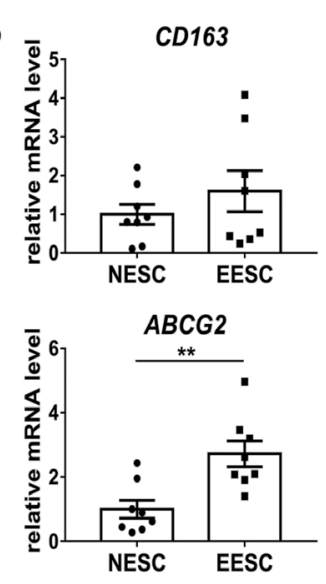

$\mathrm{C}$
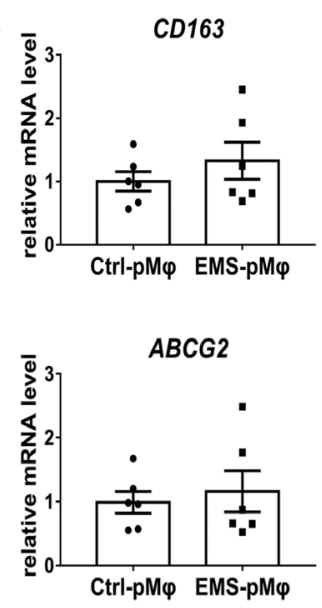
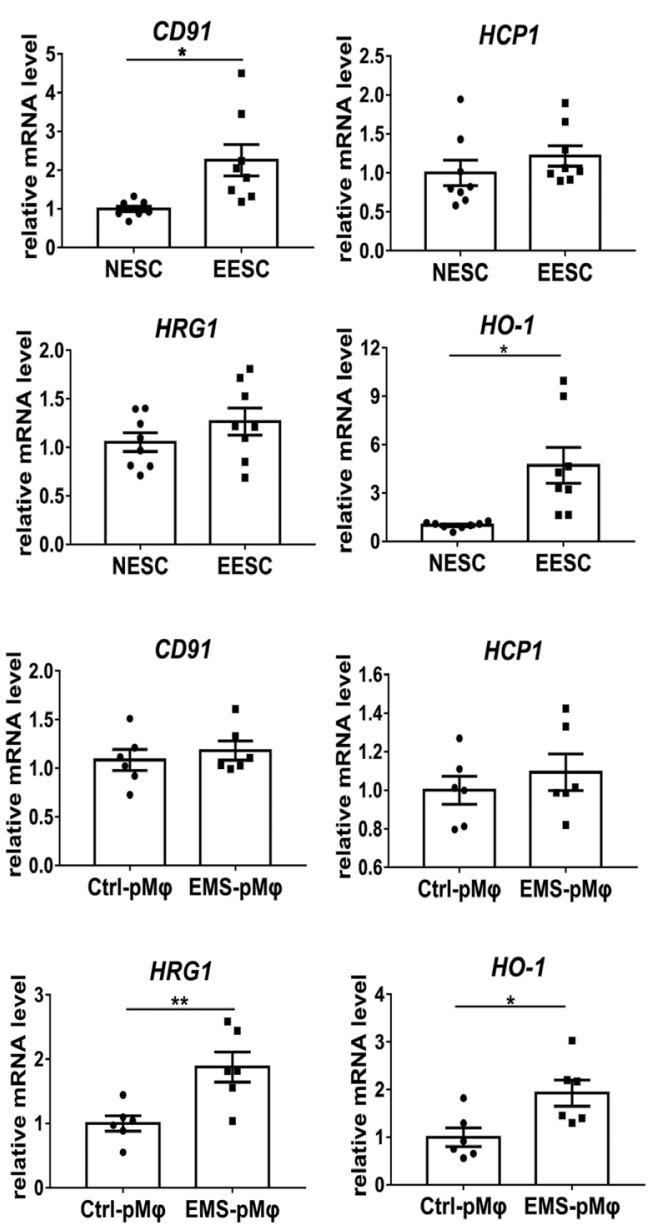
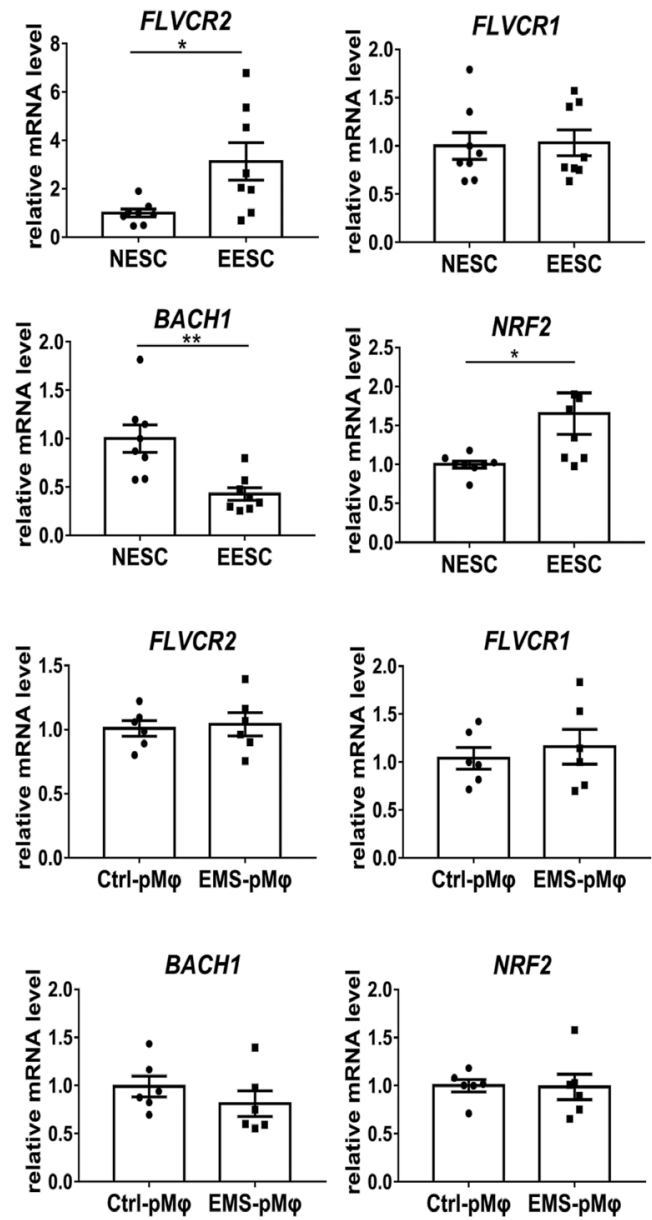

Figure 2 Heme metabolism molecules are elevated in both the ectopic ESCs and the pM $\varphi$ s of EMS. (A) A schematic diagram shows the molecules that are associated with heme metabolism. ' $\uparrow$ ': the direction of heme transport. (B and C) Relative mRNA expression of heme metabolism molecules in (B) ESCs $(n=8)$ and (C) $\mathrm{pM} \varphi(n=6)$. Data are presented as the mean \pm S.E.M.; two-tailed, unpaired $t$-test; ${ }^{*} P<0.05,{ }^{* *} P<0.01$.

iron. Iron overload has been revealed in endometriotic endometrial tissues, endometriotic cyst fluid and the PF of patients with EMS (Asghari et al. 2018). Free iron produces ROS via the Fenton reaction and also increases endometrial cells proliferation and angiogenesis in EMS (Scutiero et al. 2017). Until now, most previous 
A

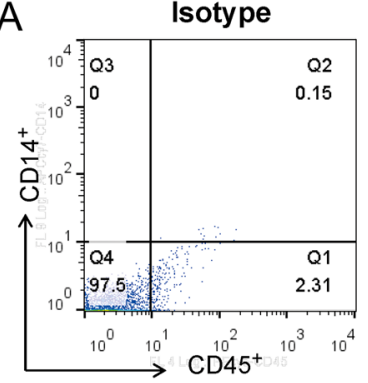

B
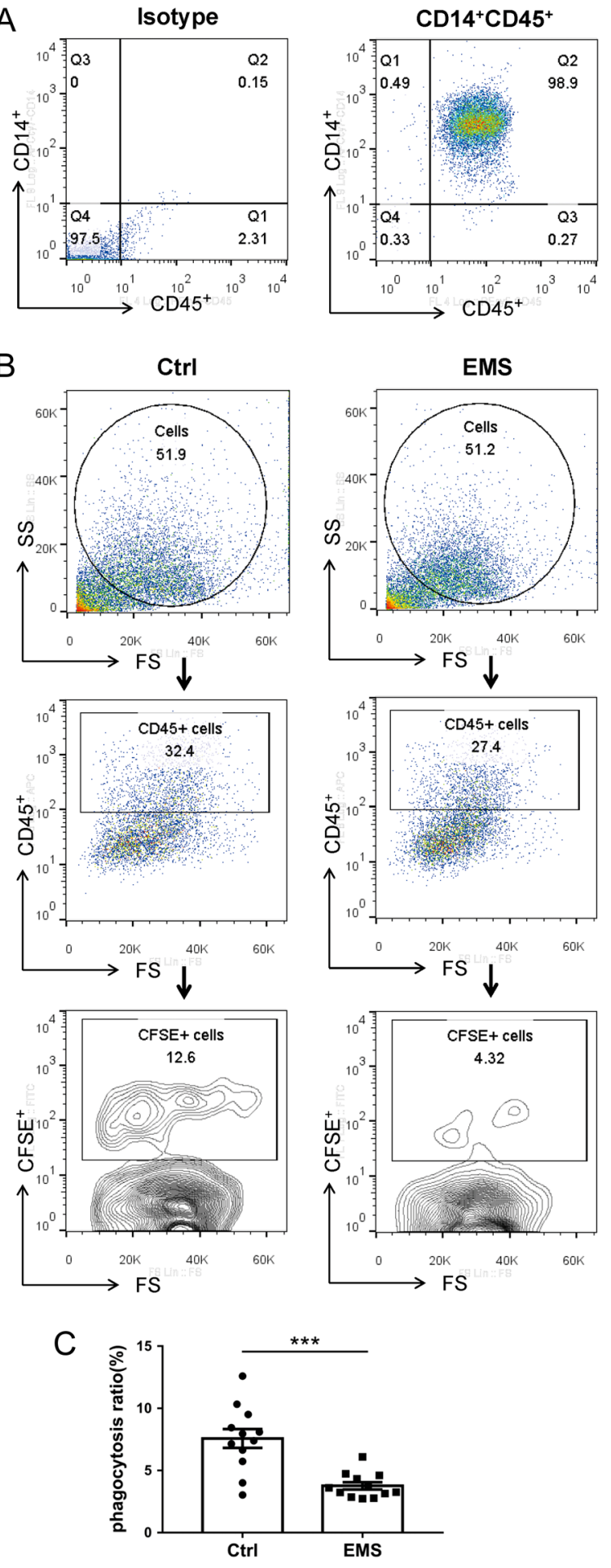

Figure 3 Phagocytosis of pM $\varphi$ s is reduced in patients with EMS. (A) Representative image of the purity of magnetically isolated $\mathrm{pM} \varphi \mathrm{s}$ using FCM. The number is the percentage of $\mathrm{CD} 14^{+} \mathrm{CD} 45^{+}$cells. (B) Representative image of phagocytosis ratio of $\mathrm{pM} \varphi s$ in women with or without EMS verified by flow cytometric analysis.

Phagocytosis ratio $=\mathrm{CFSE}^{+} \mathrm{CD} 45^{+}$cells $/ \mathrm{CD} 45^{+}$cells. (C) Quantification of phagocytosis ratio of $\mathrm{pM} \varphi \mathrm{s}$ of women with or without EMS; $n=12$. Data are presented as the mean \pm S.E.M.; two-tailed, unpaired $t$-test; $* * * P<0.001$. studies have focused on the oxidative function of heme. However, these studies did not assess the immunological function which may facilitate the intense inflammatory response and may be involved in the impaired immune surveillance in EMS.

Emerging evidences has demonstrated how heme affects the function of various immune cells including macrophages (Martins \& Knapp 2018, Zhong \& Yazdanbakhsh 2018). Heme can activate macrophages and induce the pro-inflammatory cytokines or chemokines including tumor necrosis factor (TNF), leading to neutrophil migration. Heme has also been revealed to activate the nucleotide-binding domain, leucine-rich repeat and pyrin domain-containing protein 3 (NLRP3) inflammasome and upregulate TLRdependent pro-inflammatory responses in murine macrophages (Vijayan et al. 2018). Additionally, heme can regulate the phagocytic potential of macrophages. In Martins research, human and murine macrophages undergoing heme treatments exhibited strongly impaired bacterial phagocytosis, allowing for unrestrained bacterial proliferation and an impaired outcome of $E$. coli sepsis. This process requires the activation of the GTP-binding Rho family protein Cdc42 using the guanine nucleotide exchange factor DOCK8 (Martins et al. 2016). Hualin also demonstrated that heme-activated murine macrophages appeared to enhance phagocytosis (Hualin et al. 2012), the opposite result to those recorded by Martins et al. The dose of heme for the former experiment was 3, 10 and $30 \mu \mathrm{mol} / \mathrm{L}$ and subjects were human monocyte-derived and mice peritoneal macrophages. However, the latter experiment used $5 \mu \mathrm{mol} / \mathrm{L}$ of heme to treat primary rat alveolar macrophages. This indicated that the effect of heme on macrophages may vary across a variety of cell types and concentrations of heme treatment.

In our research, the existence of heme accumulation was demonstrated in patients with endometriosis, and the efficiency of macrophage phagocytosis was assessed under different heme concentration, indicating the association between heme accumulation and decreased macrophage function in EMS. Despite the vague effect of low heme concentrations, high heme treatment, which mimics the peritoneal environment in EMS patients, impaired macrophage phagocytosis and thus provides a novel perspective in the explanation of the dysfunction of macrophage in EMS. Combined with the measurement of the concentration in the $\mathrm{PF}$, the results suggest that in normal situations, viable ESCs reflux into the peritoneal cavity with retrograded blood, red blood cells rupture and a small amount of heme is released into the peritoneal cavity. Both peritoneal macrophages and recruited $\mathrm{CD} 14^{+}$Mos could eliminate excess heme and shed ESCs. In patients exhibiting EMS, a high level of heme accumulates due to the large amount of menstrual blood that is refluxed into the peritoneal cavity and the repeated hemorrhage from endometriotic lesions. 
A

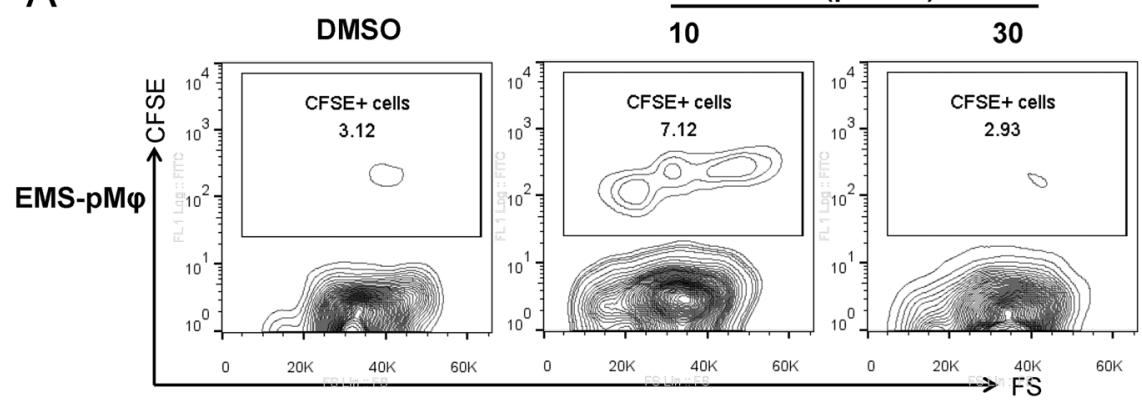

C

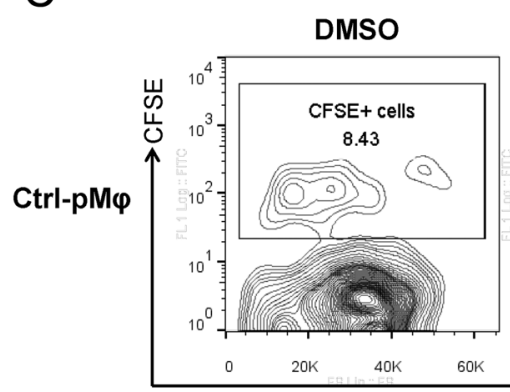

Heme ( $\mu \mathrm{mol} / \mathrm{L})$
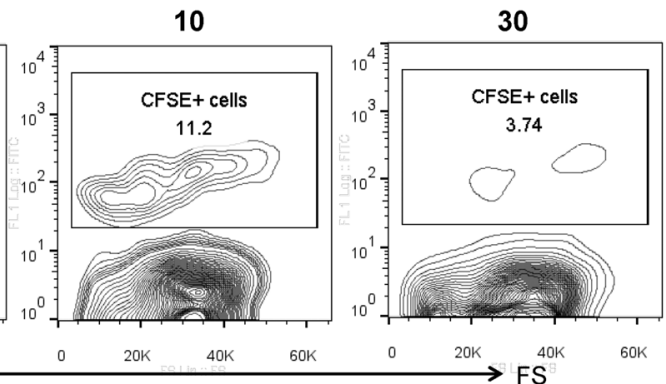

Heme ( $\mu \mathrm{mol} / \mathrm{L})$

E

DMSO

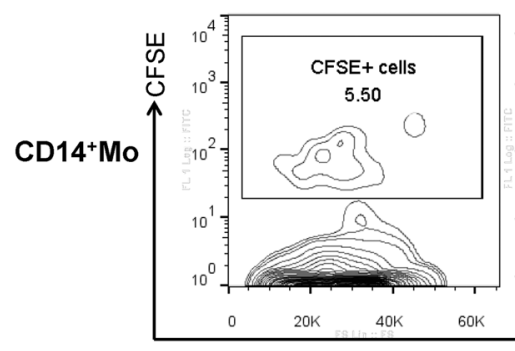

10

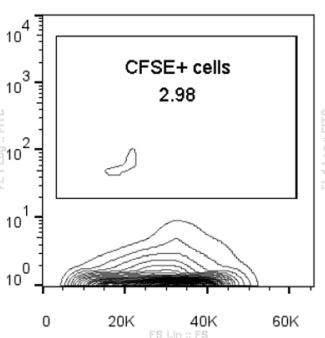

30

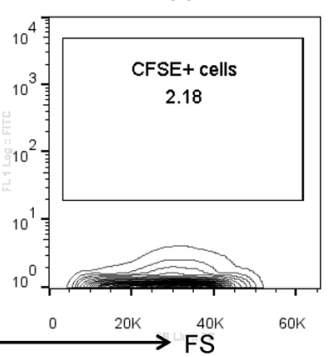

B

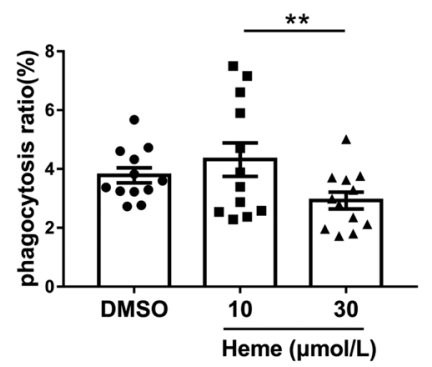

D

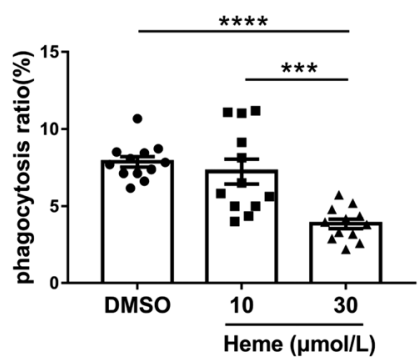

F

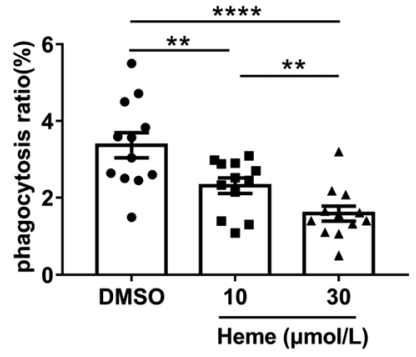

Figure 4 High level of heme impairs the phagocytic ability of macrophage. (A, C and E) Representative flow cytometric analysis of phagocytosis

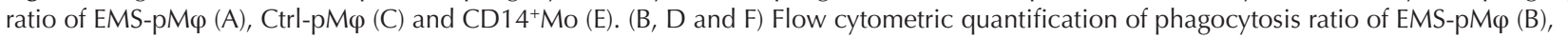

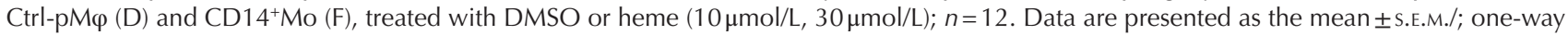
ANOVA with Turkey's multiple comparison test; ${ }^{*} P<0.05,{ }^{* *} P<0.01, * * * P<0.001,{ }^{* * * *} P<0.0001$.

High concentrations of heme can significantly impair the phagocytic potency of the recruited CD14 ${ }^{+}$Mos and resident $\mathrm{pM} \varphi \mathrm{s}$ and can lead to shed endometriotic cells remaining and finally causing endometriosis (Fig. 5).

According to previous studies, the increase of IDO1, PGE2 and IL-33, and the decrease of CD36, MMP9 and annexin A2 are associated with impaired phagocytosis of the peritoneal macrophage in EMS (Wu et al. 2005, 2013, Chuang et al. 2009, 2010, Mei et al. 2014). In particular, CD36 has been found to be regulated by heme in Alzheimer's disease, where it mediates the impaired astrocytic capacity of scavenging $\beta$-amyloid (Sankar et al. 2018). IDO1 is a hemedioxygenases enzyme that catalyzes the metabolism of L-tryptophan. L-tryptophan is also stimulated by heme and the heme byproduct iron in Mycobacterium leprae (de Mattos Barbosa et al. 2017). This study proposes the possibility that CD36 and IDO1 may be downstream molecules of heme that participates in the regulation of macrophage phagocytic function. The effects of heme on other molecules, including PGE2, IL-33 and MMP9, are quite ambiguous (Ma et al. 2017, Min et al. 2017, Lv et al. 2018) and cannot extend directly to EMS. Therefore, further work is required. Besides, the mechanisms by which EMS-pM $\varphi$ and $\mathrm{CD} 14^{+} \mathrm{Mo}$ behave differently in low heme concentration remains to be established.

To summarize, our data revealed that an excess of heme exists in the pelvic cavity of patients with EMS and this causes impaired phagocytosis of the peritoneal macrophages. This finding not only provides support for the theory of immune dysfunction in the 


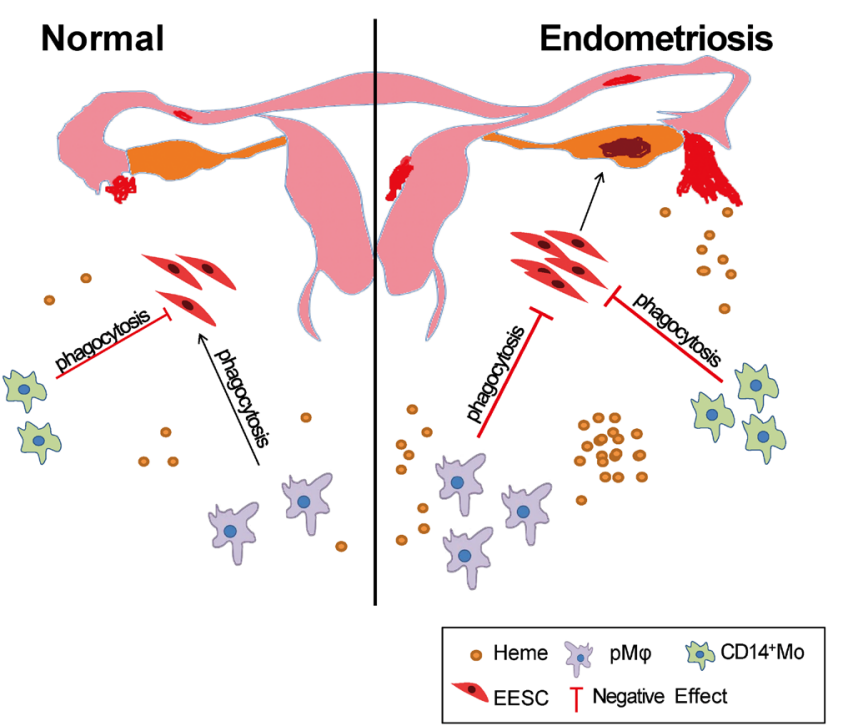

Figure 5 Schematic diagram of the key findings. This study has shown that patients with and without EMS have a particular concentration of heme in the peritoneal fluid but the concentration was higher in the EMS group. Under normal conditions, both peritoneal macrophages and recruited peripheral monocytes will eliminate the ESCs, avoiding the presence of ectopic endometrial lesions. However, when the reflux of large amounts of menstrual blood and the hemorrhage from endometriotic lesions occurred repeatedly, heme is accumulated and a high level of heme impairs the phagocytosis of macrophages. Shed ESCs are able to survive and implant, leading to EMS.

pathogenesis of EMS, but also provides new perspective in the development of improved treatments in this refractory disease.

\section{Declaration of interest}

The authors declare that there is no conflict of interest that could be perceived as prejudicing the impartiality of the research reported.

\section{Funding}

This work was supported by the National Natural Science Foundation of China (NSFC, No. 81671457 and No. 81871143 ) to Xiao-Yong Zhu, the NSFC 31671200, 91542108, 81471513, the Shanghai Rising-Star Program 16QA1400800 and the Innovation-oriented Science and Technology Grant from NPFPC Key Laboratory of Reproduction Regulation (CX2017-2) to Ming-Qing Li.

\section{Acknowledgements}

The authors thank Rongmin Wang for the collection of tissue. They also acknowledge the gynecologists at the Obstetrics and Gynecology Hospital of Fudan University for the provision of endometrial tissues and peritoneal fluid.

\section{References}

Asghari S, Valizadeh A, Aghebati-Maleki L, Nouri M \& Yousefi M 2018 Endometriosis: perspective, lights, and shadows of etiology. Biomedicine and Pharmacotherapy 106 163-174. (https://doi.org/10.1016/j. biopha.2018.06.109)

Berbic M, Schulke L, Markham R, Tokushige N, Russell P \& Fraser IS 2009 Macrophage expression in endometrium of women with and without endometriosis. Human Reproduction 24 325-332. (https://doi. org/10.1093/humrep/den393)

Chan RWS, Lee CL, Ng EHY \& Yeung WSB 2017 Co-culture with macrophages enhances the clonogenic and invasion activity of endometriotic stromal cells. Cell Proliferation 50 e12330. (https://doi. org/10.1111/cpr.12330)

Chiabrando D, Fiorito V, Petrillo S \& Tolosano E 2018 Unraveling the role of heme in neurodegeneration. Frontiers in Neuroscience 12712. (https://doi.org/10.3389/fnins.2018.00712)

Chiang SK, Chen SE \& Chang LC 2018 A dual role of heme oxygenase-1 in cancer cells. International Journal of Molecular Sciences 20 39. (https:// doi.org/10.3390/ijms20010039)

Chuang PC, Wu MH, Shoji Y \& Tsai SJ 2009 Downregulation of CD36 results in reduced phagocytic ability of peritoneal macrophages of women with endometriosis. Journal of Pathology 219 232-241. (https:// doi.org/10.1002/path.2588)

Chuang PC, Lin YJ, Wu MH, Wing LY, Shoji Y \& Tsai SJ 2010 Inhibition of CD36-dependent phagocytosis by prostaglandin E2 contributes to the development of endometriosis. American Journal of Pathology $\mathbf{1 7 6}$ 850-860. (https://doi.org/10.2353/ajpath.2010.090551)

de Mattos Barbosa MG, da Silva Prata RB, Andrade PR, Ferreira H, de Andrade Silva BJ, da Paixao de Oliveira JA, Assis TQ, de ToledoPinto TG, de Lima Bezerra OC, da Costa Nery JA et al. 2017 Indoleamine 2,3-dioxygenase and iron are required for Mycobacterium leprae survival. Microbes and Infection 19 505-514. (https://doi.org/10.1016/j. micinf.2017.06.006)

Dietrich JE, Millar DM \& Quint EH 2014 Obstructive reproductive tract anomalies. Journal of Pediatric and Adolescent Gynecology 27 396-402. (https://doi.org/10.1016/j.jpag.2014.09.001)

Donnez J, Binda MM, Donnez O \& Dolmans MM 2016 Oxidative stress in the pelvic cavity and its role in the pathogenesis of endometriosis. Fertility and Sterility 106 1011-1017. (https://doi.org/10.1016/j. fertnstert.2016.07.1075)

Duffy SP, Shing J, Saraon P, Berger LC, Eiden MV, Wilde A \& Tailor CS 2010 The Fowler syndrome-associated protein FLVCR2 is an importer of heme. Molecular and Cellular Biology 30 5318-5324. (https://doi. org/10.1128/MCB.00690-10)

Fujiwara T \& Harigae H 2015 Biology of heme in mammalian erythroid cells and related disorders. BioMed Research International 2015278536. (https://doi.org/10.1155/2015/278536)

Gambadauro P, Carli V \& Hadlaczky G 2019 Depressive symptoms among women with endometriosis: a systematic review and meta-analysis. American Journal of Obstetrics and Gynecology 220 230-241. (https:// doi.org/10.1016/j.ajog.2018.11.123)

Hahl P, Hunt R, Bjes ES, Skaff A, Keightley A \& Smith A 2017 Identification of oxidative modifications of hemopexin and their predicted physiological relevance. Journal of Biological Chemistry 292 13658-13671. (https:// doi.org/10.1074/jbc.M117.783951)

Halme J, Hammond MG, Hulka JF, Raj SG \& Talbert LM 1984 Retrograde menstruation in healthy women and in patients with endometriosis. Obstetrics and Gynecology 64 151-154.

Hualin C, Wenli X, Dapeng L, Xijing L, Xiuhua P \& Qingfeng P 2012 The anti-inflammatory mechanism of heme oxygenase- 1 induced by hemin in primary rat alveolar macrophages. Inflammation 35 1087-1093. (https://doi.org/10.1007/s10753-011-9415-4)

Immenschuh S, Vijayan V, Janciauskiene S \& Gueler F 2017 Heme as a target for therapeutic interventions. Frontiers in Pharmacology 8146. (https://doi.org/10.3389/fphar.2017.00146)

Iwabuchi T, Yoshimoto C, Shigetomi H \& Kobayashi H 2015 Oxidative stress and antioxidant defense in endometriosis and its malignant transformation. Oxidative Medicine and Cellular Longevity 2015 848595. (https://doi.org/10.1155/2015/848595)

Leeners B, Damaso F, Ochsenbein-Kolble N \& Farquhar C 2018 The effect of pregnancy on endometriosis-facts or fiction? Human Reproduction Update 24 290-299. (https://doi.org/10.1093/humupd/dmy004) 
Lv J, Su W, Yu Q, Zhang M, Di C, Lin X, Wu M \& Xia Z 2018 Heme oxygenase-1 protects airway epithelium against apoptosis by targeting the proinflammatory NLRP3-RXR axis in asthma. Journal of Biological Chemistry 293 18454-18465. (https://doi.org/10.1074/jbc. RA118.004950)

Ma YY, Yang MQ, He ZG, Fan MH, Huang M, Teng F, Wei Q \& Li JY 2017 Upregulation of heme oxygenase-1 in Kupffer cells blocks mast cell degranulation and inhibits dendritic cell migration in vitro. Molecular Medicine Reports 15 3796-3802. (https://doi.org/10.3892/ mmr.2017.6448)

Martins R \& Knapp S 2018 Heme and hemolysis in innate immunity: adding insult to injury. Current Opinion in Immunology 50 14-20. (https://doi.org/10.1016/j.coi.2017.10.005)

Martins R, Maier J, Gorki AD, Huber KV, Sharif O, Starkl P, Saluzzo S, Quattrone F, Gawish R, Lakovits K et al. 2016 Heme drives hemolysisinduced susceptibility to infection via disruption of phagocyte functions. Nature Immunology 17 1361-1372. (https://doi.org/10.1038/ni.3590)

Mei J, Xie XX, Li MQ, Wei CY, Jin LP, Li DJ \& Zhu XY 2014 Indoleamine 2,3-dioxygenase-1 (IDO1) in human endometrial stromal cells induces macrophage tolerance through interleukin-33 in the progression of endometriosis. International Journal of Clinical and Experimental Pathology 7 2743-2757.

Min H, Choi B, Jang YH, Cho IH \& Lee SJ 2017 Heme molecule functions as an endogenous agonist of astrocyte TLR2 to contribute to secondary brain damage after intracerebral hemorrhage. Molecular Brain 1027. (https://doi.org/10.1186/s13041-017-0305-z)

Parazzini F, Esposito G, Tozzi L, Noli S \& Bianchi S 2017 Epidemiology of endometriosis and its comorbidities. European Journal of Obstetrics, Gynecology, and Reproductive Biology 209 3-7. (https://doi. org/10.1016/j.ejogrb.2016.04.021)

Ponka P, Sheftel AD, English AM, Bohle DS \& Garcia-Santos D 2017 Do mammalian cells really need to export and import heme? Trends in Biochemical Sciences 42 395-406. (https://doi.org/10.1016/j. tibs.2017.01.006)

Riccio LDGC, Santulli P, Marcellin L, Abrao MS, Batteux F \& Chapron C 2018 Immunology of endometriosis. Best Practice and Research: Clinical Obstetrics and Gynaecology 50 39-49. (https://doi.org/10.1016/j. bpobgyn.2018.01.010)

Sampson JA 1927 Peritoneal endometriosis due to the menstrual dissemination of endometrial tissue into the peritoneal cavity. American Journal of Obstetrics and Gynecology 14 422-469. (https://doi. org/10.1016/S0002-9378(15)30003-X)

Sankar SB, Donegan RK, Shah KJ, Reddi AR \& Wood LB 2018 Heme and hemoglobin suppress amyloid beta-mediated inflammatory activation of mouse astrocytes. Journal of Biological Chemistry 293 11358-11373. (https://doi.org/10.1074/jbc.RA117.001050)

Scutiero G, Iannone P, Bernardi G, Bonaccorsi G, Spadaro S, Volta CA, Greco P \& Nappi L 2017 Oxidative stress and endometriosis: a systematic review of the literature. Oxidative Medicine and Cellular Longevity 2017 7265238. (https://doi.org/10.1155/2017/7265238)

Shafrir AL, Farland LV, Shah DK, Harris HR, Kvaskoff M, Zondervan K \& Missmer SA 2018 Risk for and consequences of endometriosis: a critical epidemiologic review. Best Practice and Research: Clinical Obstetrics and Gynaecology 51 1-15. (https://doi.org/10.1016/j.bpobgyn.2018.06.001)

Shao J, Zhang B, Yu JJ, Wei CY, Zhou WJ, Chang KK, Yang HL, Jin LP, Zhu XY \& Li MQ 2016 Macrophages promote the growth and invasion of endometrial stromal cells by downregulating IL-24 in endometriosis. Reproduction 152 673-682. (https://doi.org/10.1530/REP-16-0278)

Soliman AM, Surrey E, Bonafede M, Nelson JK \& Castelli-Haley J 2018 Real-world evaluation of direct and indirect economic burden among endometriosis patients in the United States. Advances in Therapy $\mathbf{3 5}$ 408-423. (https://doi.org/10.1007/s12325-018-0667-3)

Symons LK, Miller JE, Kay VR, Marks RM, Liblik K, Koti M \& Tayade C 2018 The immunopathophysiology of endometriosis. Trends in Molecular Medicine 24 748-762. (https://doi.org/10.1016/j.molmed.2018.07.004)

Van Langendonckt A, Casanas-Roux F, Dolmans MM \& Donnez J 2002 Potential involvement of hemoglobin and heme in the pathogenesis of peritoneal endometriosis. Fertility and Sterility 77 561-570. (https://doi. org/10.1016/s0015-0282(01)03211-3)

Vercellini P, Abbiati A, Vigano P, Somigliana ED, Daguati R, Meroni F \& Crosignani PG 2007 Asymmetry in distribution of diaphragmatic endometriotic lesions: evidence in favour of the menstrual reflux theory. Human Reproduction 22 2359-2367. (https://doi.org/10.1093/humrep/ dem224)

Vercellini P, Somigliana E, Vigano P, De Matteis S, Barbara G \& Fedele L 2010 Post-operative endometriosis recurrence: a plea for prevention based on pathogenetic, epidemiological and clinical evidence. Reproductive Biomedicine Online 21 259-265. (https://doi. org/10.1016/j.rbmo.2010.04.018)

Vijayan V, Wagener FADTG \& Immenschuh S 2018 The macrophage heme-heme oxygenase-1 system and its role in inflammation. Biochemical Pharmacology 153 159-167. (https://doi.org/10.1016/j. bcp.2018.02.010)

Vitale SG, Capriglione S, Peterlunger I, La Rosa VL, Vitagliano A, Noventa M, Valenti G, Sapia F, Angioli R, Lopez S et al. 2018 The role of oxidative stress and membrane transport systems during endometriosis: a fresh look at a busy corner. Oxidative Medicine and Cellular Longevity 2018 7924021. (https://doi.org/10.1155/2018/7924021)

Wei C, Mei J, Tang L, Liu Y, Li D, Li M \& Zhu X 2016 1-Methyl-tryptophan attenuates regulatory $T$ cells differentiation due to the inhibition of estrogen-IDO1-MRC2 axis in endometriosis. Cell Death and Disease 7 e2489. (https://doi.org/10.1038/cddis.2016.375)

White C, Yuan X, Schmidt PJ, Bresciani E, Samuel TK, Campagna D, Hall C, Bishop K, Calicchio ML, Lapierre A et al. 2013 HRG1 is essential for heme transport from the phagolysosome of macrophages during erythrophagocytosis. Cell Metabolism 17 261-270. (https://doi. org/10.1016/j.cmet.2013.01.005)

Wolfler MM, Meinhold-Heerlein IM, Henkel C, Rath W, Neulen J, Maass N \& Brautigam K 2013 Reduced hemopexin levels in peritoneal fluid of patients with endometriosis. Fertility and Sterility 100 777-781. (https://doi.org/10.1016/j.fertnstert.2013.05.010)

Wu M-H, Shoji Y, Wu M-C, Chuang P-C, Lin C-C, Huang M-F \& Tsai SJ 2005 Suppression of matrix metalloproteinase-9 by prostaglandin E2 in peritoneal macrophage is associated with severity of endometriosis. American Journal of Pathology 167 1061-1069. (doi:10.1016/s00029440(10)61195-9)

Wu MH, Chuang PC, Lin YJ \& Tsai SJ 2013 Suppression of annexin A2 by prostaglandin $E(2)$ impairs phagocytic ability of peritoneal macrophages in women with endometriosis. Human Reproduction 28 1045-1053. (https://doi.org/10.1093/humrep/det003)

Yang HL, Zhou WJ, Chang KK, Mei J, Huang LQ, Wang MY, Meng Y, Ha SY, Li DJ \& Li MQ 2017 The crosstalk between endometrial stromal cells and macrophages impairs cytotoxicity of NK cells in endometriosis by secreting IL-10 and TGF-beta. Reproduction 154 815-825. (https:// doi.org/10.1530/REP-17-0342)

Zhang T, De Carolis C, Man GCW \& Wang CC 2018 The link between immunity, autoimmunity and endometriosis: a literature update. Autoimmunity Reviews 17 945-955. (https://doi.org/10.1016/j. autrev.2018.03.017)

Zhong H \& Yazdanbakhsh K 2018 Hemolysis and immune regulation. Current Opinion in Hematology 25 177-182. (https://doi.org/10.1097/ $\mathrm{MOH} .0000000000000423)$

Zondervan KT, Becker CM, Koga K, Missmer SA, Taylor RN \& Vigano P 2018 Endometriosis. Nature Reviews: Disease Primers 4 9. (https://doi. org/10.1038/s41572-018-0008-5)

Received 17 January 2019

First decision 29 March 2019

Revised manuscript received 10 June 2019

Accepted 2 July 2019 